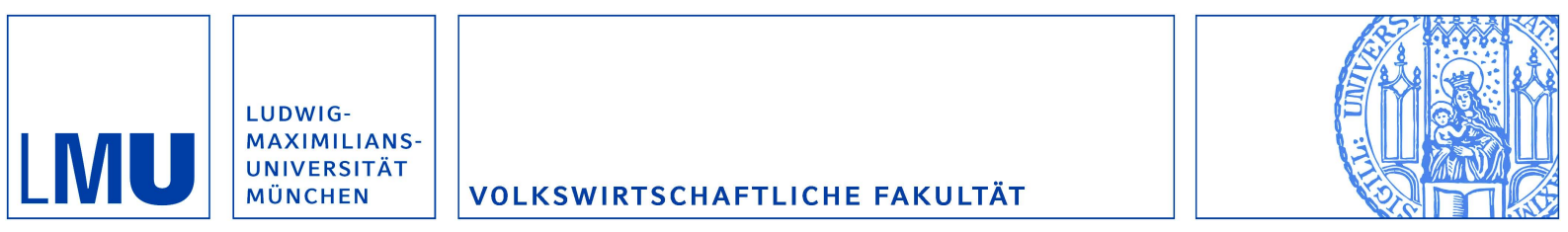

Traxler, Christian:

Social Norms and Conditional Cooperative Taxpayers

Munich Discussion Paper No. 2006-28

Department of Economics

University of Munich

Volkswirtschaftliche Fakultät

Ludwig-Maximilians-Universität München

Online at https://doi.org/10.5282/ubm/epub. 1202 


\title{
Social Norms and Conditional Cooperative Taxpayers
}

\author{
Christian Traxler* \\ University of Munich \\ Seminar for Economic Policy \\ Akademiestrasse 1/II \\ D-80799 Munich \\ First Version: October 2003 \\ This Version: September 25, 2006
}

\begin{abstract}
This paper incorporates tax morale into the Allingham Sandmo (1972) model of income tax evasion. Tax morale is interpreted as a social norm for tax compliance. The norm strength, depending on the share of evaders in the society, is endogenously derived. Taxpayers act conditionally cooperative, as their evasion decision depends on the other agents' compliance. We characterize an equilibrium which accounts for this interdependence and study the impact of tax and deterrence policies on compliance. Our analysis is then extended to the case of a society which consists of heterogenous communities where individual evasion decisions are embedded in a complex social structure. In this scenario, behavior is crucially influenced by the norm compliance among morale reference groups. Within this framework, we discuss the role of belief management and belief leadership as alternative policy tools.
\end{abstract}

JEL classification: H26; Z13; K42.

Keywords: Tax Evasion; Tax Morale; Social Norms; Conditional Cooperation.

*E-mail: christian.traxler@lrz.uni-muenchen.de; Phone/Fax: +49 892180 -3303/-6296 


\section{Introduction}

In the past two decades, a huge body of empirical literature has emerged which highlights the importance of tax morale - taxpayers' attitudes, perceptions and moral values - for individual evasion decisions. ${ }^{1}$ Tax evasion seems to be more than a risky gamble of rational individuals, who trade off the costs from detection with the chance of getting away undetected (Allingham and Sandmo, 1972). ${ }^{2}$ As expressed by Agnar Sandmo (2005, p.649), "people refrain from tax evasion [...] not only from their estimates of the expected penalty, but for reasons that have to do with social and morale considerations." One crucial factor which systematically influences such moral considerations is the (perceived) compliance of other taxpayers: Individuals, who believe that most fellow citizens are honest, consider evasion as a more serious wrongdoing than those, who presume tax evasion to be more widespread. ${ }^{3}$ As recently discussed by Frey and Torgler (2006), this link also seems to be causal: Higher expectations about the level of evasion result, ceteris paribus, in a lower tax morale (and not the other way around).

In this paper we take up these findings and incorporates tax morale into Allingham and Sandmo's (1972) analysis of income tax evasion. Tax morale is modeled as an internalized social norm for tax compliance (Elster, 1989). The norm works as a soft constraint on action which render evasion 'costly'. If a taxpayer deviates from the norm and conceals income, conduct is not in line with the individual's self-image as a 'good' member of society, who complies with societal norms and expectations. The strength of the norm - and thereby the self-imposed sanctions associated with a norm violation - is determined by two factors: First, by an exogenously given, individual specific degree of norm internalization. Second, by the endogenously determined share of evaders in the society. The more people deviate from the norm, the weaker the compliance norm becomes. This creates an interdependency of evasion decisions. An increase in evasion will trigger a bandwagon effect as it lowers the strength of the norm and thereby raises other taxpayers' disposition to dodge taxes. Hence, individuals act conditionally cooperative - they condition their compliance on the behavior of other members of the society. ${ }^{4}$

We first discuss the policy implications of this framework for the case of a homogenous society. In a next step, we extend our analysis to the case of a more structured society, consisting of different subgroups. The strength of the social norm is not only determined by the behavior among the own peers, but also by the compliance in other subgroups. Within such a structured society, different communities can end up with quite different levels of tax compliance. Hence, this framework captures community specific 'tax subcultures', as discussed in Lewis (1982). Moreover, we show that group specific policy changes create spillovers on other communities. The intuition for this result is that conditional cooperation works not only within but also between groups. If, for example, looser tax enforcement among one specific group results in more evasion, this creates an externality on the norm strength in other groups. The more a community takes over the position of a social reference group, the more detrimental are norm

\footnotetext{
${ }^{1}$ Compare e.g. Alm et al. (1992), Alm and Torgler (2006), Baldry (1986), Gërxhani and Schram (2005), Güth et al. (2005), Kirchler et al. (2003), Lewis (1982, 1986), Torgler and Schneider (2005). Compare also chapter 6 in Cowell (1990) and Torgler (2006).

${ }^{2}$ See Andreoni et al. (1998) and Cowell (1990) for comprehensive discussions of the classical evasion model.

${ }^{3}$ See e.g. Frey and Torgler (2006), Porcano (1988), Spicer and Hero (1985), Torgler and Schneider (2005).

${ }^{4}$ Compare Gächter (2006) who provides a comprehensive survey of experimental as well as field evidence of conditional cooperative behavior.
} 
violations within this group on the perceived norm strength in the rest of the society. In order to maintain a strong social norm, it is therefore crucial to enforce a high level of tax compliance among 'morale leaders', i.e. members of moral reference groups. If the 'leaders' adhere to the norm, this will trigger conditional compliance among the 'followers'. This last result can be neatly linked to recent experimental evidence which studies the impact of leader behavior in groups. Gächter and Renner (2006), for example, show that higher contributions by a leader (first-mover) in a sequential public good game make followers expect higher levels of cooperation. In turn, this results in more contributions among the followers. The importance of such a leaderfollower interaction is also emphasized by Hammar et al. (2005). They report on a study by the Swedish Tax Agency which found that "the most common argument legitimizing tax evasion among Swedens is that those in leading positions in society violate the social norms" (p.5).

Comparing our approach to the standard model of tax evasion, we solve several shortcomings of the latter. First, standard theory can not explain that a majority of households fully complies with tax laws. As most fiscal systems are characterized by rather low audit rates and penalties, a rational, immoral taxpayers with a reasonable degree of risk aversion should conceal at least some income (Bernasconi, 1998). Obviously, we can account for the high levels of compliance documented in many countries, ${ }^{5}$ once we allow tax morale to play a role. Second, the Allingham Sandmo model can hardly explain huge differences in tax compliance between countries or regions with comparable monetary incentives for evasion. Stated more provocatively, standard theory fails to explain why 'Palermo is not Milan and Stockholm is not Moscow' (Rothstein, 2000). As noted above, the evasion decisions in our model are interdependent - taxpayers will conceal more income, the more other taxpayers deviate from the compliance norm. This behavioral pattern typically results in a multiplicity of equilibria. An economy with a given tax and enforcement policy can either end up in a state with a strong social norm, where most taxpayers pay all their taxes honestly, or a state with a weak social norm, where evasion is more widespread. In this vein, a model with an endogenous norm strength provides one explanation to the 'Palermo-Milano puzzle'.

Thirdly, our model solves another weakness of the standard model. For the plausible assumption of decreasing absolute risk aversion, the standard theory implies that higher taxes will lead to a lower level of evasion. If the penalty imposed on detected evaders is proportional to the concealed income, a tax increase does not trigger any substitution effect, as both the gains from evasion as well as the costs (associated with a higher expected fine) rise (Yitzhaki, 1974). The negative income effect then makes taxpayers less willing to bear risks. Therefore, they will conceal less income. We demonstrate that this counterintuitive result which is also at odds with most empirical studies (e.g. Clotfelter, 1983), vanishes in our model, if individuals are strongly affected by the social norm. Moral taxpayers conceal 'too little' income, such that the marginal expected return from evasion is positive. Any tax increase then further raises the marginal return from cheating and thereby provides an incentive to extend the level of evasion. We can find a threshold, where this substitution effect outbalances the income effect and the counterintuitive result turns around - evasion is then increasing in the tax rate.

\footnotetext{
${ }^{5}$ Compare e.g. Alm et al. (1992), Andreoni et al. (1998).
} 
Finally, our framework also allows for quite unusual responses to policy changes, if agents are not perfectly rational in the formation of their beliefs about others' behavior. If, for example, a stricter deterrence policy is accompanied by a shock in agents' beliefs such that they expect a level of norm violations which is above the true level, these initially false beliefs can become self-fulfilling. In the context of multiple equilibria, stricter deterrence could then trigger more evasion. This finding also points out the role of belief management as an important policy instrument (compare e.g. Fehr and Falk, 2002; Gächter, 2006).

There are several other contributions which study behavioral models of tax evasion. ${ }^{6}$ Three of them are closely related to our approach. Kim (2003) examines a model of stigmatization in case of detected evasion. While the properties of his framework are similar to ours, he uses numerical simulations to show results that we can derive analytically. Myles and Naylor (1996) consider a social norm (respectively a social custom) for tax compliance. In contrast to our approach, however, they assume that the disutility from a norm deviation is independent of the amount of evasion. Their model suggests that those who cheat on taxes all choose an optimal level of evasion as predicted by Allingham and Sandmo (1972). Hence, they neither capture heterogenous levels of non-compliance nor a positive relationship between the tax rate and evasion. The analysis by Gordon (1989) is most closely related to our study. The preference structure considered in the present paper, however, is less specific than the one in Gordon (1989). In addition, we provide a detailed examination of tax and deterrence policies in the context of interrelated evasion decisions which is missing in Gordon (1989). Furthermore, neither Gordon (1989) nor any other paper studies evasion in a multi-group setting or the role of belief management.

The remainder of the paper is structured as follows. In the next section we briefly present the Allingham and Sandmo (1972) model as a starting point for our analysis. In section 3 we introduce a tax compliance norm and study individual evasions behavior within this framework. Section 4 provides an equilibrium concept for a heterogenous population of taxpayers. In section 5 , we extend our model to a society consisting of different subgroups, and demonstrate how group specific policy measures cause spillovers on other subgroups of the society. The paper concludes with the discussion of a policy application.

\section{The Allingham-Sandmo Model}

Following Allingham and Sandmo (1972) (hereafter labeled AS), we consider individuals with an exogenous gross income $y$. Each taxpayer $i$ decides on how much of this income to declare and how much to conceal. Income concealed is labeled $e_{i} \in[0, y]$. The declared income, $y-e_{i}$, gets taxed with a proportional income tax at rate $\tau$. With a fixed probability $p$ the evasion gets detected. In this case, the tax evader has to pay the full taxes and a penalty which is proportional to the taxes evaded (Yitzhaki, 1974). With probability $1-p$ the evasion remains undetected and the evader only pays taxes on the declared income. The corresponding levels of net income $x_{i}$ for state $a$ - getting detected - respectively state $b$ - escaping undetected - are

\footnotetext{
${ }^{6}$ E.g. Bordignon (1993), Cullis and Lewis (1997), Erard and Feinstein (1994), Falkinger (1995), Schnellenbach (2006).
} 
given by

$$
\begin{aligned}
x_{i}^{a} & =x^{a}\left(e_{i}\right)=y-\left(y-e_{i}\right) \tau-\tau e_{i}-\tau e_{i} s=(1-\tau) y-\tau e_{i} s \\
x_{i}^{b} & =x^{b}\left(e_{i}\right)=y-\left(y-e_{i}\right) \tau=(1-\tau) y+\tau e_{i}
\end{aligned}
$$

where $s>0$ denotes the penalty rate. The expected (monetary) utility from evasion is given by the von Neumann-Morgenstern

$$
E\left[u\left(x\left(e_{i}\right)\right)\right]=p u\left(x^{a}\left(e_{i}\right)\right)+(1-p) u\left(x^{b}\left(e_{i}\right)\right)
$$

with $u^{\prime}(x)>0$ and $u^{\prime \prime}(x)<0$. Agents choose $e$ so as to maximize expected utility. Note that this decision is equivalent to an optimal portfolio choice problem, as individuals decide on how much of their income to declare - and thereby invest in a safe asset - and how much to conceal - invest in a risky asset. The first- and second-order condition to this problem are given by

$$
\begin{aligned}
E[u]^{\prime} & \equiv-p s \tau u^{\prime}\left(x^{a}\right)+(1-p) \tau u^{\prime}\left(x^{b}\right)=0, \\
E[u]^{\prime \prime} & \equiv p(s \tau)^{2} u^{\prime \prime}\left(x^{a}\right)+(1-p) \tau^{2} u^{\prime \prime}\left(x^{b}\right)<0 .
\end{aligned}
$$

Condition (2) characterizes $e^{A S}$, the optimal level of income concealed. We will assume in the following that such an interior solutions $e^{A S} \in[0, y]$ always exits.

Implicitly differentiating $E[u]^{\prime}$ with respect to $p$ and $s$, one can easily show that the level of evasion decreases as tax enforcement becomes stricter, i.e. $d e^{A S} / d p<0$ and $d e^{A S} / d s<0$ respectively. The effect of a marginal increase in $\tau$ is given by

$$
\frac{d e^{A S}}{d \tau}=\frac{(1-p) \tau u^{\prime}\left(x^{b}\right)\left[(y-e)\left(\rho\left(x^{b}\right)-\rho\left(x^{a}\right)\right)-e(s+1) \rho\left(x^{b}\right)\right]}{-E[u]^{\prime \prime}}
$$

where we made use of (2) and the Arrow-Pratt measure of absolute risk aversion, $\rho(x)=$ $-u^{\prime \prime}(x) / u^{\prime}(x)$. For the case of non-increasing absolute risk aversion $\rho^{\prime} \leq 0$ and therefore $\rho\left(x_{i}^{a}\right) \geq$ $\rho\left(x_{i}^{b}\right)$. Hence, the sign in the squared brackets in (4) is negative. We get the paradoxical result $d e^{A S} / d \tau<0$. According to the AS-framework, taxpayers with constant or decreasing absolute risk aversion conceal less income, if the tax rate rises. This counterintuitive finding is driven by the structure of the fine. Here we follow Yitzhaki (1974), who assumes that the penalty is assessed on the level of taxes evaded, rather than income concealed, as in the original AS paper. An increase in taxes will therefore raise both, the marginal gain from undetected evasion, i.e. taxes saved, as well as the marginal costs associated with higher fines in the case of detection. In the optimum, these two effects exactly offset each other. There is no substitution effect and the impact of a tax increase on the optimal evasion level is solely driven by the income effect. In the case of decreasing absolute risk aversion, a rise in taxes will reduce evasion, as a lower income makes taxpayers less willing to bear risks.

We take this finding as a benchmark, and show that it might vanish if taxpayers are not only guided by monetary incentives but also by moral concerns as defined below. In order to guarantee comparability of the analysis, we maintain the assumption of non-increasing absolute risk aversion throughout the paper. 


\section{A Social Norm for Tax Compliance}

We now incorporate tax morale into the decision problem. Tax morale is modeled as an internalized social norm for tax compliance - or equivalently, a norm against evasion. Declaring all income correctly is considered to be the 'morally right' behavior, while cheating on the taxes represents a violation of a social norm. Each member of the society has internalized these moral connotations to a certain degree. If a taxpayer conceals income, behavior is in conflict with morals. Tax evasion is then accompanied by internal sanctions, associated with emotions like guilt or remorse (Elster, 1989). The strength of these internal sanctions depends on the endogenous strength of the norm. Following the literature (e.g. Akerlof, 1980), we assume that a norm is perceived as stronger, the more people adhere to it. If tax evasion becomes more common, the social norm is less powerful and individuals' costs to deviate from the norm decline: It becomes easier for taxpayers to justify their wrong-doing to themselves, the more other people violate the societies' code of conduct. As we have discussed in the introduction, this line of reasoning is supported by ample empirical evidence which shows that individuals consider tax evasion more justifiable, the more they believe that other citizens cheat on taxes (see e.g. Frey and Torger, 2006).

We considering the following additive preference structure

$$
v\left(e_{i}, \theta_{i}\right)=E\left[u\left(x\left(e_{i}\right)\right)\right]-\theta_{i} e_{i} c(n) .
$$

While $E[u()$.$] represents the expected utility defined in (1), \theta_{i} e_{i} c(n)$ capture the 'moral costs' of tax evasion, associated with emotional sanctions. Note that negative emotions are assumed to occur irrespectively whether the evasion gets detected or not. Hence, there is no risk associated with this latter payoff. ${ }^{7}$ Our approach further assume that individuals rationally trade off the (expected) monetary benefits from evasion with the non-pecuniary costs from a norm violation. ${ }^{8}$

The costs of evasion depend on (i) $\theta_{i} \geq 0$, the individual specific degree of norm internalization, as well as (ii) the continuous function $c(n)$ which captures the strength of the norm for a given share of tax evaders $n$ in the society. We assume that $0<c(n)<\infty$ and $c^{\prime}(n) \leq 0$ for $n \in[0,1]$. The more taxpayer deviate from the norm, the lower are the moral costs of evasion. Moreover, (iii) the moral costs are linearly increasing in $e_{i}$, the amount of income concealed by agent $i .^{9}$

\subsection{Optimal Evasion Decision}

Taking the policy variables as well as the number of evaders $n$ as given, an agent maximizes $v\left(e_{i}, \theta_{i}\right)$ with respect to $e_{i}$. The first order condition for an interior solution is

$$
-p s \tau u^{\prime}\left(x_{i}^{a}\right)+(1-p) \tau u^{\prime}\left(x_{i}^{b}\right)=\theta_{i} c(n) .
$$

\footnotetext{
${ }^{7}$ In the case of stigmatization studied by Kim (2003), the non-monetary costs from evasion of course depend upon whether an individual gets detected or not.

${ }^{8}$ Empirical evidence which supports this assumption is provided by e.g. Bosman and van Winden (2002), Hopfensitz and van Winden (2006).

${ }^{9}$ Empirical support for the case that taxpayers distinguish between different levels of evasion is provided by Aitken and Bonneville (1980) and Lewis (1986). Note further, that any non-linearity would only change our results quantitatively.
} 
The second order condition is equivalent to (3). As the left hand side of (6) equals $E[u]^{\prime}$ from (2), we can express condition (6) as $E[u]^{\prime}=\theta_{i} c(n)$. Norm guided taxpayers will choose a level of evasion such that $E[u]^{\prime}$, the marginal expected utility, equals $\theta_{i} c(n)$, the marginal moral costs from an increase in the level of income concealed. Homo oeconomicus does not care about norms or morals, i.e. $\theta_{i}=0$. Such an agent chooses an optimal portfolio according to (2), increasing evasion up to the point where the marginal expected utility is equal to zero. This yields the level of evasion predicted by the AS framework, $e^{A S}$. In contrast, taxpayers with high levels of $\theta_{i}$ may be in a corner solution and refrain from evasion. Let us define the marginal expected utility for the first unit of evasion,

$$
z \equiv E[u(x(0))]^{\prime}=(1-p(1+s)) \tau u^{\prime}((1-\tau) y),
$$

with $z>0 .{ }^{10}$ From (3) and (6) it then follows that taxpayers with $\theta_{i} c(n)>z$ do not conceal any income. From this follows the threshold

$$
\hat{\theta}(n) \equiv \frac{z}{c(n)},
$$

which allows us to characterize the optimal individual evasion behavior $\hat{e}_{i}$ for a given level of $n$ :

$$
\hat{e}_{i}=\left\{\begin{array}{ll}
0 & \text { for } \theta_{i}>\hat{\theta}(n) \\
e_{i}^{*} & \text { for } \theta_{i} \leq \hat{\theta}(n)
\end{array} .\right.
$$

Individuals with $\theta_{i}>\hat{\theta}(n)$ will stick to the compliance norm. On the other hand, those with $\theta_{i} \leq$ $\hat{\theta}(n)$ will choose an interior solution $e_{i}^{*}$ according to condition (6). A graphical representation of the optimal evasion level is provided below.

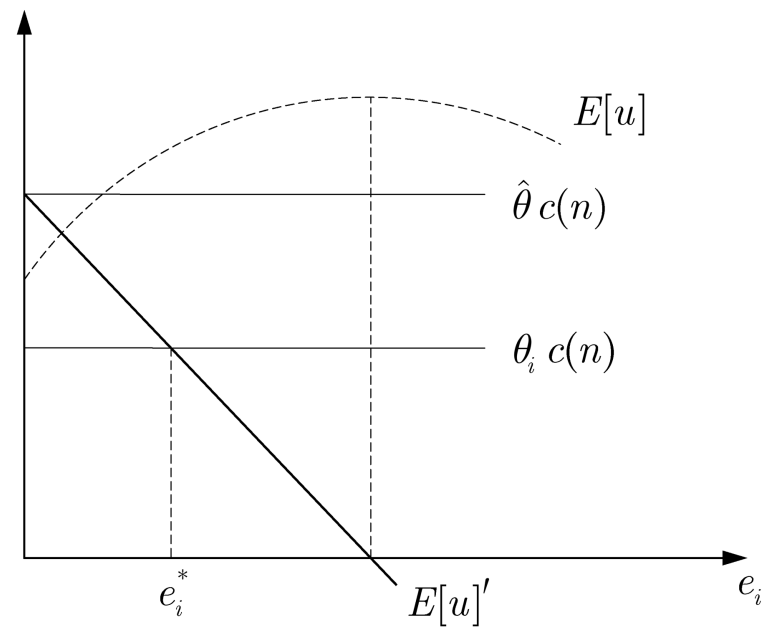

Figure 1: Optimal Evasion with a Social Norm

Figure 1 pictures expected utility as well as the marginal moral costs of evasion on the

\footnotetext{
${ }^{10}$ For $z<0$ there would have to hold $(1-p(1+s))<0$. If this were the case, evasion would not be a 'fair gamble', in the sense that concealing income yields a negative expected return. The enforcement policy would be deterrent, as no taxpayer would conceal any income.
} 
vertical axis against income concealed, plotted on the horizontal axis. ${ }^{11}$ While an agent with $\theta_{i}=\hat{\theta}(n)$ will adhere to the compliance norm, taxpayers with $\theta_{i}=0$ will choose $e^{A S}$ which maximizes the expected utility $E[u]$. Individuals with $0 \leq \theta_{i} \leq \hat{\theta}(n)$, however, will choose an intermediate level of evasion, $e_{i}^{*} \in\left[0, e^{A S}\right]$. Note that $e_{i}^{*}$ depends - next to the policy variables $p, s, \tau$, income $y$ and norm sensitivity $\theta_{i}$ - also on the $n$, the share of evaders in a society. Hence, evasion decisions are interdependent. Before we characterize an equilibrium which accounts for this interdependency in the next section, we first provide a brief comparative static analysis.

\subsection{Partial Equilibrium Analysis}

Let us treat for the moment the frequency of evaders $n$ as an exogenous variable. Applying the implicit function theorem on (6) we then get

$$
\begin{aligned}
\frac{\partial e_{i}^{*}}{\partial p} & =\frac{s \tau u^{\prime}\left(x_{i}^{a}\right)+\tau u^{\prime}\left(x_{i}^{b}\right)}{E[u]^{\prime \prime}}<0, \\
\frac{\partial e_{i}^{*}}{\partial s} & =\frac{p \tau\left(u^{\prime}\left(x_{i}^{a}\right)-s \tau e_{i}^{*} u^{\prime \prime}\left(x^{a}\right)\right)}{E[u]^{\prime \prime}}<0 \\
\frac{\partial e_{i}^{*}}{\partial \theta_{i}} & =\frac{c(n)}{E[u]^{\prime \prime}}<0 \\
\frac{\partial e_{i}^{*}}{\partial n} & =\frac{\theta_{i} c^{\prime}(n)}{E[u]^{\prime \prime}} \geq 0
\end{aligned}
$$

with $E[u]^{\prime \prime}$ as defined in (3). As in the AS framework, stricter enforcement will reduce evasion. Raising the penalty or the audit rate will induce agents to declare more income. Next to the formal tax enforcement institution, also the social norm has a deterrent effect: An exogenous shock in the norm sensitivity $\theta_{i}$ will result in a lower level of evasion. In terms of figure 1 , the $\theta_{i} c(n)$ line would shift upwards and $e_{i}^{*}$ would decline. Furthermore, (13) shows that taxpayers condition their evasion on the behavior of others. As more people evade taxes, agents with $0<\theta_{i} \leq \hat{\theta}(n)$ react by concealing more income. The more taxpayers deviate from the compliance norm, the weaker is the social norm, the lower are the moral cost of concealing. In this sense, any new tax evader creates a positive externality on all other cheaters - it makes their wrong-doing more justifiable, and thereby provides an incentive to evade more. From (8) we can derive

$$
\frac{\partial \hat{\theta}(n)}{\partial n}=-\hat{\theta}(n) \frac{c^{\prime}(n)}{c(n)} \geq 0
$$

since $c^{\prime}(n) \leq 0$. With a higher level of $n$, the compliance threshold $\hat{\theta}(n)$ rises. Some agents with $\theta_{i} \geq \hat{\theta}(n)$, who used to refrain from evasion, will start to conceal income after an increase in $n$. These taxpayers condition their compliance with the tax law on the behavior of others. They act as conditional cooperative taxpayers. We will elaborate on the implications of this behavior in the following section.

\footnotetext{
${ }^{11}$ While in general $E[u]^{\prime}$ is non-linearly decreasing in $e_{i}$, we plotted a linear form for the sake of graphical simplicity.
} 
Let us now turn to the impact of a tax increase. From (6) we obtain

$$
\frac{\partial e_{i}^{*}}{\partial \tau}=\frac{1}{-E[u]^{\prime \prime}}\left\{\frac{\theta_{i} c(n)}{\tau}+p s \tau u^{\prime \prime}\left(x_{i}^{a}\right)\left(y+s e_{i}^{*}\right)-(1-p) \tau u^{\prime \prime}\left(x_{i}^{b}\right)\left(y-e_{i}^{*}\right)\right\} .
$$

Note that for $\theta_{i}=0$ the first term in the curly brackets is zero, and the right hand side is equivalent to the effect derived in the AS framework, depicted in (4). In this case, we would get $\partial e_{i}^{*} / \partial \tau<0$. However, for positive values of $\theta_{i}$ the result might turn around. In Appendix A1, we derive from (15) a threshold $\tilde{\theta}(n)$, such that

$$
\frac{\partial e_{i}^{*}}{\partial \tau} \begin{cases}\geq 0 & \text { for } \theta_{i} \geq \tilde{\theta}(n) \\ <0 & \text { for } \theta_{i}<\tilde{\theta}(n)\end{cases}
$$

While for low levels of $\theta_{i}$ the counterintuitive effect from the AS model carries over to our framework, the result turns around for agents with a sufficient strong tax morale: As $\theta_{i}>\tilde{\theta}(n)$ we get the more plausible result that tax evasion increases with a higher tax rate. Moreover, in the appendix we show that $\tilde{\theta}(n)$ is increasing in the levels of norm deviations. The lower the share of tax evaders in the society, the lower is $\tilde{\theta}(n)$ and thereby $\partial e_{i}^{*} / \partial \tau \geq 0$ holds for a broader range of $\theta$-values. Note, however that non-increasing absolute risk aversion implies $\tilde{\theta}(n)>0$. Hence, there is always a range $\theta \in[0, \tilde{\theta}(n)]$ where the counterintuitive comparative static from AS carries over to our framework.

The intuition for this finding is straightforward. As we have discussed above, a tax increase will raise the marginal benefits from evasion, as well as the marginal costs (associated with higher expected fines). For the optimal evasion level predicted by AS these two effects offset each other. There is no substitution effect and the income effect from higher taxation triggers a reduction in the evasion level. In our context, however, we find a positive substitution effect for all agents with $\theta_{i}>0$ (depicted in the first term in the curly brackets in (15)). These agents will choose an evasion level such that $E[u]^{\prime}>0$. Marginal expected benefits from concealing are above marginal expected costs. In terms of optimal portfolio choice, moral taxpayers 'over-invest' into the safe asset - they conceal too little and declare too much income. Any increase in the tax rate then raises the wedge between marginal expected benefits and cost even further. This raises marginal expected utility $E[u]^{\prime}$ for all agents with $\theta_{i}>0$ (respectively $e_{i}^{*}<e^{A S}$ ). As we have assumed moral costs of evasion to depend on income concealed rather than taxes evaded, these costs are not affected by a tax change. Hence, the substitution effect provides a clear incentive to increase evasion. ${ }^{12}$ While the negative income effect is still present, the positive substitution effect dominates for $\theta_{i}>\tilde{\theta}(n)$. For these agents, tax evasion increases as taxes rise. Note that this result is not new in the literature. Our analysis solely replicates the result from Gordon (1989) in a more compact framework.

Figure 2 provides a graphical representation of the partial equilibrium effects associated with an increase in the tax rate. From the definition of $z$ above, one can easily derive $\partial z / \partial \tau>0$. From the AS model we know that $E[u]^{\prime}$ evaluated at $e_{i}^{A S}$ decreases with an increase of the tax rate. Hence, the $E[u]^{\prime}$ curve turns clockwise as we increase $\tau$, with the turning-point somewhere

\footnotetext{
${ }^{12}$ If moral costs would depend on the level of taxes evaded, a higher tax rate would also raise the evasion costs. As long as the increase in marginal expected utility dominates the increase in costs, we would still observe a raise in the evasion level for some levels of $\theta$.
} 


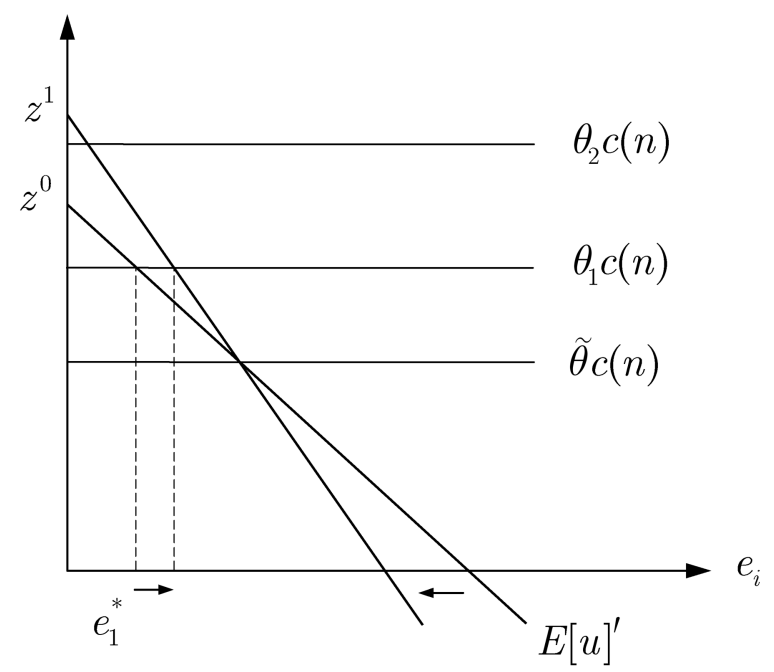

Figure 2: Partial Equilibrium Effect of a Tax Increase

between $e_{i}^{A S}$ and $e_{i}=0$. (Note that this also implies $0<\tilde{\theta}(n)<\hat{\theta}$.) The intersection of the marginal expected utility curve before and after the change in the tax rate defines the threshold $\tilde{\theta}(n)$. In the example from figure 2 , individuals with $\theta_{i}<\tilde{\theta}(n)$ will reduce evasion as the tax rate raises. The taxpayer with e.g. $\theta_{1}>\tilde{\theta}(n)$, however, will conceal more income. Moreover, taxpayer 2, who has been paying all taxes honestly before the tax increase, will switch to an interior solution after the policy change. From this example one can also see that a change in one policy variable typically has an impact on the share of evaders. In the following we study this effect in an equilibrium framework.

\section{Social Equilibrium}

We consider a continuum population with unit mass. The norm parameter $\theta$ is distributed according to a continuously differentiable, cumulative distribution function $F(\theta)$ which has full support on the interval $[0, \bar{\theta}]$. The corresponding density function is $f(\theta)$ and the inverse of the distribution function is denoted $F^{-1}(n)$. As we know from (9), people choose to evade taxes if $\theta_{i} \leq \hat{\theta}(n)$. The equilibrium population share of evaders $n^{*}$ is then given by the fixed-point equation

$$
n^{*}=F\left(\frac{z}{c\left(n^{*}\right)}\right)
$$

The right hand side of (17) is a continuous function in $n$, mapping the compact interval $[0,1]$ into itself. Assuming $\bar{\theta} c(1) \geq z$ assures that there always exists at least one asymptotically stable equilibrium $n^{*} \in(0,1],{ }^{13}$ where stability is given iff

$$
\left.\frac{\partial F^{-1}(n)}{\partial n}\right|_{n^{*}} \geq\left.\frac{\partial \hat{\theta}(n)}{\partial n}\right|_{n^{*}} .
$$

\footnotetext{
${ }^{13}$ The existence of an equilibrium hinges on $\bar{\theta} \geq \hat{\theta}(1)$ as well as $\hat{\theta}(0)>0$. Note, that an equilibrium with $n^{*}=0$ is not supported, as we allow for taxpayers with $\theta_{i}=0$ who always choose to evade $e^{A S}>0$ for any level of $n$.
} 
For an exogenous policy $\mathbf{P}=(\tau, p, s)$, an equilibrium characterizes a self supporting share of evaders. For $n^{*}$, the strength of the norm is such that a population share of $1-n^{*}$ will declare their income honestly, while the remaining $n^{*}$ will choose an interior solution $e_{i}^{*}$ as characterized by (6). While there is at least one solution to (17), the system is typically characterized by a multiplicity of equilibria. Such a case is illustrated in figure 3. If evasion has become prevalent, the compliance norm has practically eroded and society finds itself in an equilibrium where nearly everybody cheats on taxes. For the same policy $\mathbf{P}$ and distribution $F(\theta)$, however, the society could in principle coordinate on a different equilibrium, where most agents adhere to the norm. The social norm would be stronger and the level of tax evasion in the society would be smaller.

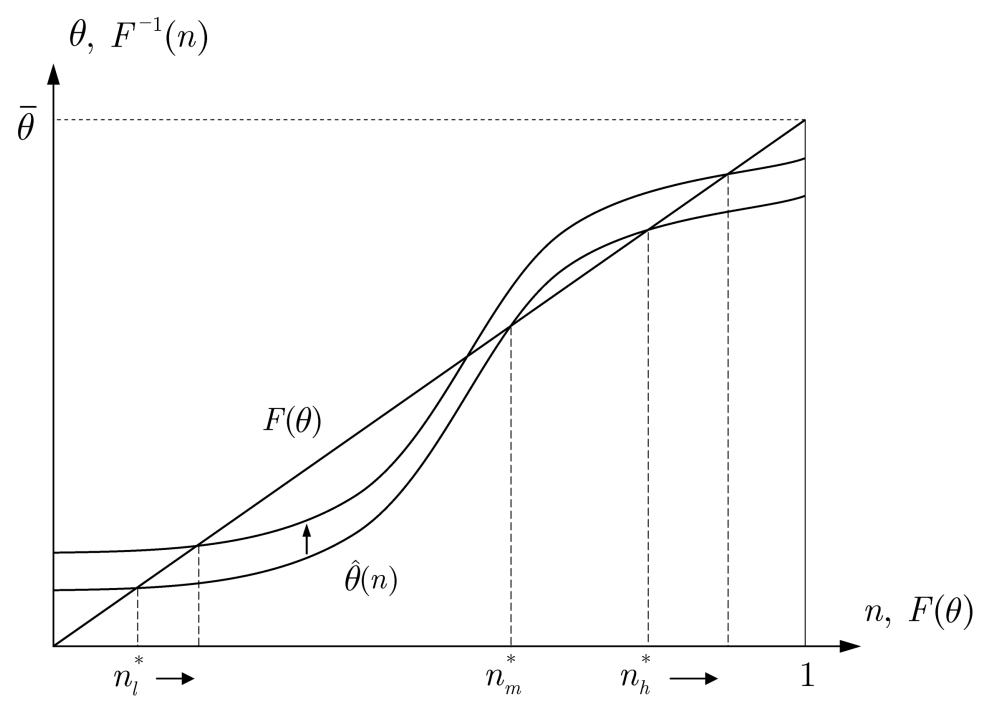

Figure 3: Social Equilibrium - Impact of a Tax Increase

In figure 3 we plot the share of norm violators $n$ on the horizontal axis against the degree of norm internalization $\theta$ respectively the threshold $\hat{\theta}(n)$ on the vertical axis. In the example, we consider a uniform distributed of $\theta$. The shape of $\hat{\theta}(n)$ is defined by the function $c(n)$. In figure 3 there are two asymptotically stable equilibria - a 'good' one, where only a small fraction $n_{l}^{*}$ deviates from the norm and a 'bad' equilibrium with widespread evasion, $n_{h}^{*}$. Between these two stable equilibria, there is a third, instable one, with $n_{m}^{*}$. Such instable equilibria mark the boundaries of a stable equilibriums' basin of attraction. In our example, society would converges into the good equilibrium, starting from any share $n \in\left[0, n_{m}^{*}\right]$, respectively into the bad equilibrium, for any $n \in\left[n_{m}^{*}, 1\right]$. We will come back to this point in section 4.3.

\subsection{Equilibrium Effect of a Tax Increase}

Let us take a look at the equilibrium effect of an increase in the tax rate. As already addressed above, individuals with $\theta_{i}>\hat{\theta}(n)$ may switch from a corner solution to an interior solution after a tax increase. These new evaders will weaken the social norm, moral costs of evasion decline and further taxpayers will start concealing income. The equilibrium effect is captured by an upward shift of the $\hat{\theta}(n)$-curve in figure 3: the marginal expected utility from concealing the first unit of income increases $(\partial z / \partial \tau>0)$. Accordingly, the evasion threshold $\hat{\theta}(n)$ rises for any 
$n$ which results in an increase in the stable equilibrium share of evaders. Analytically, we can derive this from (17) and get

$$
\frac{d n^{*}}{d \tau}>0
$$

for any stable equilibrium (see Appendix A2). The equilibrium impact on the optimal level of evasion is then given by

$$
\frac{d e_{i}^{*}}{d \tau}=\frac{\partial e_{i}^{*}}{\partial \tau}+\frac{\partial e_{i}^{*}}{\partial n} \frac{d n^{*}}{d \tau}
$$

with $\partial e_{i}^{*} / \partial n$ and $\partial e_{i}^{*} / \partial \tau$ from (13) respectively (15). As we have shown above in (16), the sign of the first order effect is ambiguous and depends on the norm parameter $\theta_{i}$. In contrast, the second order effect is unambiguously positive for all $\theta_{i}>0$. We can derive a new threshold $\tilde{\theta}^{*}\left(n^{*}\right)$ (see Appendix A2) such that

$$
\frac{d e_{i}^{*}}{d \tau} \begin{cases}\geq 0 & \text { for } \theta_{i} \geq \tilde{\theta}^{*}\left(n^{*}\right) \\ <0 & \text { for } \theta_{i}<\tilde{\theta}^{*}\left(n^{*}\right)\end{cases}
$$

In equilibrium, there are now two effects which tend to raise evasion. First, there is a positive substitution effect, discussed in the partial equilibrium analysis above. Second, a tax increase is accompanied by an increase in the equilibrium share of norm breaking individuals. This second effect lowers the moral cost of evasion and thereby provides a further incentive to conceal more income. For taxpayers with $\theta_{i} \geq \tilde{\theta}^{*}\left(n^{*}\right)$ these two effects dominate the negative income effect they will react with more evasion on an increase in the tax rate. From this discussion also follows that $\tilde{\theta}^{*}<\tilde{\theta}$ for any $n^{*} .{ }^{14}$ Hence, compared to the partial equilibrium analysis, $d e_{i}^{*} / d \tau \geq 0$ holds for a broader range of $\theta$-values.

\subsection{Equilibrium Effect of Deterrence Policies}

We now turn to the impact of the tax enforcement variables $s$ and $p$ on the equilibrium share of evaders as well as on the equilibrium level of evasion. From (17) we derive in Appendix A2 that in a stable equilibrium there holds

$$
\frac{d n^{*}}{d p}<0, \quad \frac{d n^{*}}{d s}<0
$$

As the deterrence policy becomes stricter, the marginal expected utility from evasion - and therefore also $z$ - falls; thereby, also the threshold $\hat{\theta}(n)$ decreases (compare (7) respectively (8)). The $\hat{\theta}(n)$-curve shifts downward and the population share of evaders drops. Using (22), we then get the equilibrium impact of a stricter enforcement policy,

$$
\begin{aligned}
\frac{d e_{i}^{*}}{d p} & =\frac{\partial e_{i}^{*}}{\partial p}+\frac{\partial e_{i}^{*}}{\partial n} \frac{d n^{*}}{d p}<0, \\
\frac{d e_{i}^{*}}{d s} & =\frac{\partial e_{i}^{*}}{\partial s}+\frac{\partial e_{i}^{*}}{\partial n} \frac{d n^{*}}{d s}<0
\end{aligned}
$$

Additional to the first-order effects $\partial e_{i}^{*} / \partial p$ and $\partial e_{i}^{*} / \partial s$ derived above in (10) and (11), the deterrence policy now has a second order effect. As auditing becomes more frequent or if the

\footnotetext{
${ }^{14}$ As this new effect is strictly positive, $d e_{i}^{*} / d \tau>0$ also holds when the income dominates the substitution effect.
} 
penalty rates increases, the resulting drop in the share of evaders makes the social norm for tax compliance stronger - the moral costs of tax evasion increase. This will trigger a further reduction in the level of evasion. Hence, in our framework, the equilibrium impact of tax enforcement is stronger than suggested by the partial equilibrium analysis, respectively the AS model.

\subsection{Beliefs and Multiple Equilibria}

So far, we have considered the case where any (marginal) policy change results in a marginal adjustment of $n^{*}$. In the context of multiple equilibria, however, this is not necessarily true. Our analysis implicitly assumes (a) that there always exists a stable equilibrium in the close neighborhood of the previous one and (b) that society indeed coordinates on this particular equilibrium. The first assumption is fulfilled, as long as the stability condition from (18) holds with strict inequality. Regarding the second point, one could argue that - at least for minor policy changes - an equilibrium which is 'proximate' to the former one is more salient than an alternative, more distant equilibrium. Following this line of reasoning, the equilibrium in the neighborhood of the previous one becomes a focal point equilibrium (Schelling 1960). If this is the case, (19)-(24) provide the valid marginal effects of the policy variables. If assumption (b) is violated, however, these results can turn around.

To illustrate this point, assume that individual behavior is based on beliefs rather than the true level of norm-violations. Let us denote a taxpayer's belief about $n$ at time $t$ by $b_{i}^{t}=$ $b\left(n^{t-1}, \phi_{i}^{t-1}, \mathbf{P}\right)$. Beliefs depend on the past level of norm violations, the policy vector $\mathbf{P}$, as well as a parameter $\phi_{i}^{t-1}$ which captures an individuals specific perceptions at time $t-1$. We assume $\partial b^{t} / \partial n^{t-1}>0$ and $\partial b^{t} / \partial \phi^{t-1}>0$. Hence, with a shock in beliefs $\phi_{i}^{t-1}>0$ a taxpayer tends to overestimate the level of evaders. In equilibrium there holds $\phi_{i}^{t-1}=0$ and $b_{i}^{t}=b\left(n^{*}, 0, \mathbf{P}\right)=n^{*}$ $\forall i$. It is worth noting that in the absence of shocks beliefs would always adapt such that they would be fulfilled in the long run, i.e. $b_{i}^{t}=n^{*}$ as $t \rightarrow \infty$. Starting from any initial (offequilibrium) level $n^{0}$ within the basin of attraction of one particular, stable equilibrium (e.g. $n \in\left[0, n_{m}^{*}\right]$ for equilibrium $n_{l}^{*}$ in figure 3$)$, the updating of beliefs based upon $n^{t-1}$ will drive behavior towards this equilibrium.

Let us first consider the case where stricter tax enforcement - e.g. an increase in the detection probability - is announced at period $t$ and there is no shock on agents' beliefs $\left(\phi_{i}^{t}=0\right)$. Starting from an equilibrium $n_{0}^{*}$, perfectly informed taxpayer would adjust their behavior according to the new, weaker evasion incentives. The level of evaders drops, and so will agents' beliefs in the following period. The social norm becomes stronger, providing a further incentive to reduce evasion. Society gradually move towards the new stable equilibrium $n_{1}^{*}<n_{0}^{*}$. This case is also illustrated in figure 4 . Stricter enforcement shifts the $\hat{\theta}(n)$-curve downwards which reduces the level of non-compliance in any stable equilibrium.

Consider now a scenario with belief shocks. More frequent audits are announced 'as a response to the high level of non-compliance' and some agents take this as a signal that the current evasion level is higher than originally believed. If their 'mistake' $\phi_{i}^{t}>0$ is large enough,

their belief after the policy change $\mathbf{P} \rightarrow \mathbf{P}^{\prime}$ fulfills $b_{i}^{t+1}\left(n_{0}^{*}, \phi_{i}, \mathbf{P}^{\prime}\right)>b\left(n_{0}^{*}, 0, \mathbf{P}\right)$. Hence, these agents perceive an increase in the level of norm deviations. The compliance norm becomes weaker which provides an incentive to conceal more rather than less income. Given that this 
latter incentive dominates the direct effect from stricter auditing, the number of evaders would raise among those with $\phi_{i}^{t}>0$. As a result, we might observe an overall increase in norm violations, i.e. $n^{t+1}>n_{0}^{*}$. Nevertheless, society would converge towards the equilibrium $n_{1}^{*}$, if (i) no further shocks occur $\left(\phi_{i}^{t+1}=\phi_{i}^{t+2}=\ldots=0\right.$ ) and (ii) $n^{t+1}$ is still in the basin of attraction of the equilibrium $n_{1}^{*}$. In a society with many stable equilibria, however, each equilibrium's basin of attraction becomes relatively small. Already minor shocks could then be sufficient to push $n^{t+1}$ into the attraction area of a different equilibrium. In figure 4, for example, it would be sufficient if $n^{t+1}>n_{m}^{*}$ which provides the upper limit of the basin of attraction to $n_{1}^{*}$. If norm violations after the shock overshoot this level, the system converges towards the stable equilibrium $n_{2}^{*}$ - an equilibrium with more evaders than before the policy change.

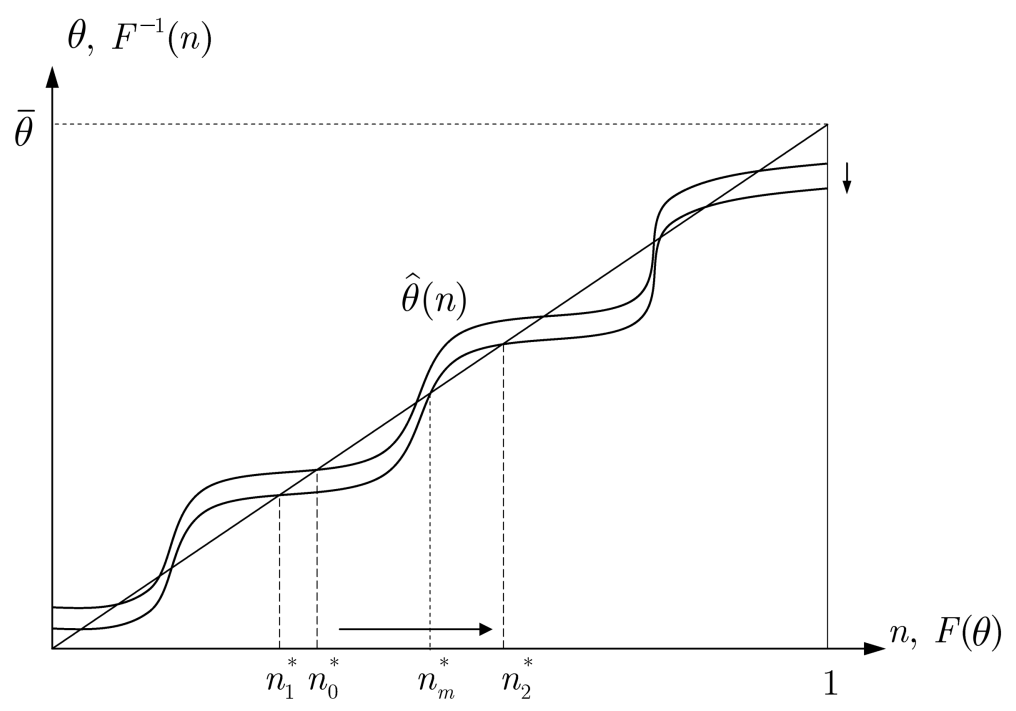

Figure 4: Response to stricter Enforcement - Belief Shocks

As this thought experiment shows, stricter tax enforcement can trigger more evaders, such that the results from (22) turn around. This also renders the enforcement variables' impact on the actual level of evasion ambiguous: The negative direct effect from an increase in $p$ or $s$, depicted in the first terms on the RHS of (23) respectively (24), would work against the positive effect from a weakening of the social norm, related to an increase norm-violations. For evaders with a high norm-sensitivity $\theta$, the latter effect is more likely to dominate the monetary incentives for compliance.

As we have seen, policy adjustments in the context of multiple equilibria can trigger counterintuitive behavioral responses, once we allow for belief shocks. The original incentive related to a policy change are more likely to be turned around, either if shocks are large or in the case where many stable equilibria exist. The immediate policy implication of this discussion is straightforward: taxpayers' beliefs matter! Hence, the management of these beliefs become a policy tool. New policies should therefore be communicated in a way which either tries to avoid shocking beliefs at all or tries to shock beliefs in a direction which supports the policy change. Turning back to the example from above, it might be more efficient to announce increased auditing efforts as a means 'to further improve the high level of compliance' rather than as response to 'a recent increase in tax evasion'. We will come back to the impact of belief management in the following section. 


\section{Social Structure and Inter-Group Spillovers}

In this section we extend our basic framework and analyze a more complex structure of society. In particular, we consider a population consisting of $M \geq 2$ subgroups. One could think of these groups as local communities or social classes with similar education, income or social status. In the following we focus on the case where individuals within a group $j \in\{1, \ldots, M\}$ have the same income $y_{j}$ and face the same policy $\mathbf{P}_{j}=\left(\tau_{j}, p_{j}, s_{j}\right)$. The net income of agent $i$ from group $j$ for the case of detected respectively undetected evasion is then given by

$$
\begin{aligned}
& x_{i j}^{a}=x_{j}^{a}\left(e_{i j}\right)=\left(1-\tau_{j}\right) y_{j}-\tau_{j} e_{i j} s_{j}, \\
& x_{i j}^{b}=x_{j}^{b}\left(e_{i j}\right)=\left(1-\tau_{j}\right) y_{j}+\tau_{j} e_{i j} .
\end{aligned}
$$

The preferences are described by

$$
v_{j}\left(e_{i j}, \theta_{i j}\right)=E\left[u\left(x\left(e_{i j}\right)\right)\right]-\theta_{i j} e_{i j} \sum_{k=1}^{M} \alpha_{j k} c\left(n_{k}\right)
$$

with

$$
\begin{gathered}
E\left[u\left(x\left(e_{i j}\right)\right)\right]=p_{j} u\left(x_{j}^{a}\left(e_{i j}\right)\right)+\left(1-p_{j}\right) u\left(x_{j}^{b}\left(e_{i j}\right)\right), \\
\sum_{k} \alpha_{j k}=1 \forall_{j}
\end{gathered}
$$

and $n_{k} \in[0,1]$ denotes the share of evaders in group $k \in\{1, \ldots, M\}$. In (25) we allow the moral costs of evasion to depend upon the compliance behavior in the own as well as other groups of society. The parameter $\alpha_{j k} \in[0,1)$ thereby captures the sensitivity of the norm strength in community $j$ with respect to norm deviations in group $k$. We exclude the special case $\alpha_{j j}=1$, where the norm is group specific in the sense that its' strength depends exclusively on the behavior within the own group. Hence, there always exists (at least) one subgroup $k \neq j$ with $\alpha_{j k}>0$ which works as a moral role model or moral reference group for agents from $j .{ }^{15}$

\subsection{Optimal Evasion and Social Equilibrium}

Assuming that communities are large and policies as well as non-compliance levels are taken as given, individuals choose $e_{i j}$ in order to maximize (25). Analogously to (6), the first order condition for an interior solution is

$$
-p_{j} s_{j} \tau_{j} u^{\prime}\left(x_{i j}^{a}\right)+\left(1-p_{j}\right) \tau_{j} u^{\prime}\left(x_{i j}^{b}\right)=\theta_{i j} \sum_{k} \alpha_{j k} c\left(n_{k}\right)
$$

The threshold for an interior solution becomes

$$
\hat{\theta}_{j}\left(n_{j}, n_{-j}\right)=\frac{z_{j}}{\sum_{k} \alpha_{j k} c\left(n_{k}\right)}
$$

with $z_{j} \equiv\left(1-p_{j}\left(1+s_{j}\right)\right) \tau_{j} u^{\prime}\left(\left(1-\tau_{j}\right) y_{j}\right)>0$ and $n_{-j}=\left(n_{1}, \ldots, n_{j-1}, n_{j+1}, \ldots, n_{M}\right)$. For $\theta_{i j} \leq \hat{\theta}_{j}\left(n_{j}, n_{-j}\right)$, condition $(27)$ characterizes the optimal evasion level $e_{i j}^{*}$. All agents with $\theta_{i j}$

\footnotetext{
${ }^{15}$ If moral costs were shaped by the pattern of direct social interactions, we could relate $\alpha_{j k}$ to the degree of population segregation respectively viscosity (Myerson et al., 1991). If $\alpha_{j k}$ is high, the interaction frequency between types from groups $j$ and $k$ is high.
} 
above this threshold are in a corner solution and fully comply with tax laws.

We can now describe a social equilibrium for a society structured in $M$ groups. Let the degree of norm internalization within each group be distributed according to a continuously differentiable, cumulative distribution function $F_{j}(\theta)$ with $\theta_{i j} \in[0, \bar{\theta}]$ and the inverse $F_{j}^{-1}$ is well defined on the unit interval. A social equilibrium is then characterized by $\left(n_{j}^{*}, n_{-j}^{*}\right)$ with

$$
n_{j}^{*}=F_{j}\left(\hat{\theta}_{j}\left(n_{j}^{*}, n_{-j}^{*}\right) \quad \forall_{j}\right.
$$

and stability is given iff

$$
\left.\frac{\partial F_{j}^{-1}}{\partial n_{j}}\right|_{n_{j}=n_{j}^{*}} \geq\left.\frac{d \hat{\theta}_{j}\left(n_{j}, n_{-j}\right)}{d n_{j}}\right|_{n_{j}=n_{j}^{*}, n_{-j}=n_{-j}^{*}} \forall_{j}
$$

Assuming that $\hat{\theta}_{j}\left(1, n_{-j}\right)<\bar{\theta}$ holds for $n_{-j}=(1, \ldots, 1)$, there always exists at least one stable equilibrium. ${ }^{16}$

In section 4, there was always one equilibrium associated with one norm strength for the whole society. The extended framework now allows for equilibria where the perceived strength of the social norm as well as behavior strongly differs between heterogeneous subgroups of society. In particular, social structure and inter-group links could support social equilibria, where some groups predominantly cheat on taxes while most members of other communities act according to the norm. The model thereby captures what Lewis (1982, p.144) described as different coexisting 'tax subcultures'.

\subsection{Policy Spillovers and Belief Leadership}

We now turn to policy changes within this extended framework. To simplify the formal analysis, we consider a society with only two groups, i.e. $M=2$. Let us first study an increase in the tax rate for group $j$. As before, we can derive that

$$
\frac{d n_{j}^{*}}{d \tau_{j}}>0
$$

holds in any stable equilibrium. ${ }^{17} \mathrm{~A}$ tax increase still induces more people to cheat on taxes. However, a higher level of $n_{j}^{*}$ now has a negative impact on the perceived norm strength in the other group $k \neq j$ and thereby triggers further norm deviations. In particular, we get from (29)

$$
\frac{d n_{k}^{*}}{d n_{j}^{*}}>0
$$

As taxpayers condition their compliance also on the behavior in the other group, norm deviations within $j$ create a spillover on community $k$.

The adjustment in evasion among members from the subgroup targeted by the tax increase is given by

$$
\frac{d e_{i j}^{*}}{d \tau_{j}}=\frac{\partial e_{i j}^{*}}{\partial \tau_{j}}+\left(\frac{\partial e_{i j}^{*}}{\partial n_{j}}+\frac{\partial e_{i j}^{*}}{\partial n_{k}} \frac{d n_{k}^{*}}{d n_{j}^{*}}\right) \frac{d n_{j}^{*}}{d \tau_{j}} .
$$

\footnotetext{
${ }^{16} \mathrm{As} c(0)$ is finite, there holds $\hat{\theta}_{j}\left(0, n_{-j}\right)>0$ for all $n_{-j}$. This implies the existence of a stable social equilibrium.

${ }^{17}$ All results of this section are derived in Appendix A3.
} 
One can derive the partial equilibrium effects $\partial e_{i j}^{*} / \partial \tau_{j}$ and $\partial e_{i j}^{*} / \partial n_{j}>0$ analogously to the ones presented in section 4 . The impact of an increase in $\tau_{j}$ on the evasion level of agents from group $j$ is similar as before: Next to the direct impact on the monetary incentives to evade, higher taxes will raise the share of norm violations within the own group. In turn, the compliance level in the other subgroup will decrease as well. With a higher share of evaders in both communities the strength of the social norm declines. Since $\partial e_{i j}^{*} / \partial n_{k} \geq 0$, this provides a similar second order incentive to increase $e_{i j}^{*}$ as discussed in the previous section. In addition, however, the group specific tax policy creates an externality on compliance in the other group:

$$
\frac{d e_{i k}^{*}}{d \tau_{j}}=\left(\frac{\partial e_{i k}^{*}}{\partial n_{j}}+\frac{\partial e_{i k}^{*}}{\partial n_{k}} \frac{d n_{k}^{*}}{d n_{j}^{*}}\right) \frac{d n_{j}^{*}}{d \tau_{j}} \geq 0 .
$$

Although the change in the tax rate does not alter the monetary incentives of these taxpayers, they react with an increase in evasion. As more taxpayers from the other community start cheating, tax morale among the own peers - and thereby compliance - drops as well. Again, this result is triggered by conditional cooperative taxpayers. In the basic framework this effect occurred within one group - a homogenous society. Now it works between different subgroups of the population. As a consequence, any group specific policy change will causes a spillover on other communities within the society. ${ }^{18}$ The magnitude of the externality from a change in policy $\mathbf{P}_{j}$ on the level of evasion in group $k \neq j$ is determined by the social role a community $k$ plays for the members of $j$. The higher is $\alpha_{j k}$, the more weight is attributed to the behavior of agents from $k$ in determining tax morale within group $j$, the stronger is the spillover. Hence, the more a group works as a moral reference group for others, the more crucial are norm violations among that group.

This observation has several important implications. First, the behavior of those with high social and moral prestige can have a huge impact on tax compliance in the rest of the population. Empirical evidence which supports this conjecture is discussed by Hammar et al. (2005). They also report on a study by the Swedish Tax Agency which found that "the most common argument legitimizing tax evasion among Swedens is that those in leading positions in society violate the social norms" (p.5). Second, the spillovers provide new arguments for optimal policy choice. A revenue maximizing enforcement policy, for example, should ceteris paribus devote more resources on auditing members from moral reference groups. Enforcing high levels of compliance among these groups creates strong, positive spillovers and thereby yields high tax revenues. Furthermore, the spillovers could also present a limitation for optimal redistributive taxation. Given that social prestige is associated with higher incomes, our analysis suggests that taxing the rich would also cause a decline in tax morale and therewith compliance in the rest of the society. A thorough analysis of this tradeoff is left for further research.

Note further that the 'leading groups' in a society are typically rather small. Hence, the norm violations of a few could then lead to a sharp erosion of tax morale within the whole society. We could easily find examples, where rather small shifts in the behavior within a moral reference group eliminate the existence of 'good' equilibria (with a high level of norm compliance) for other subgroups. Some few tax evasion cases among 'morale leaders' - societies' high-profile

\footnotetext{
${ }^{18}$ Note, that this analysis is based upon the same implicit assumptions as discussed in section 4.3. If we allow for belief shocks, it becomes unclear upon which equilibrium a society would coordinate after a policy change.
} 
members like politicians - could then shift a bulk of the population from an equilibrium state with a large extent of tax compliance to a state with widespread evasion.

The crucial role of leadership is also highlighted by recent experimental economic studies. For example, Gächter and Renner (2006) show how contributions of a leader (first-mover) in a sequential public good game affect the followers' beliefs and thereby their behavior. Higher contributions by the leaders make followers expect higher levels of cooperation which triggers more contributions among conditional cooperators. Similar evidence is discussed in Arbak and Villeval (2006). Hence, these studies point out the role of belief leadership as one possible way to manage beliefs (compare section 4.3). ${ }^{19}$

\section{Conclusion}

In order to design appropriate policies to ensure tax compliance, it is essential to carefully examine taxpayers' motivation to comply with tax laws. This paper studies the incentives related to tax morale, interpreted as a social norm for compliance. As empirical research demonstrated, taxpayers' inclination to cheat on taxes crucially depends on the (perceived) behavior of their fellow citizens. The more others evade taxes, the easier it is justifiable to conceal income. This way, individual decisions become interdependent. Taxpayers act conditionally cooperative, i.e. they condition their compliance on the behavior of other members of the society.

As we have shown, our framework improves upon the classical tax evasion model in several respects. We can explain rather high levels of compliance despite weak tax enforcement. As an endogenous norm strength typically implies the existence of multiple equilibria, the model also allows for different levels of evasion for one fixed monetary incentive to conceal income. In a society which consists of several distinct communities, this implies the possibility of different, coexisting tax subcultures. Finally, our approach also allows for a positive and thereby more intuitive relation between tax rates and the level of evasion.

Next to conventional fiscal policy variables, the paper also discusses the role of belief management. In a world of conditional cooperative taxpayers, it are not only the monetary incentives which influence evasion decisions, but also individual beliefs. Any measure which corroborates beliefs in high compliance levels therefore forms a potentially important policy instrument. Belief leadership constitutes one tool to manage beliefs. As we have analyzed in the case of a structured, multi-group society, the norm compliance in moral reference groups is of crucial importance for tax morale in many other communities. If 'moral leaders' start to violate the norm, strong detrimental spillovers on the perceived norm strength in the whole society can occur. Hence, enforcing high level of compliance among 'leaders' helps to ensure compliance among 'followers'.

Recently, the applicability of belief management has been demonstrated by Fellner et al. (2006). In a natural field experiment, they sent mailings to potential evaders of public broadcasting licence fees and measured how many evaders started to pay the fees. Among others, they compare the success of a neutral letter to a letter which contained information about the high level of compliance with licence fees. Their evidence suggests that the information-letter was more successful than the neutral one for individuals who experienced a positive shock in their

\footnotetext{
${ }^{19}$ The role of belief management is also discussed in Fehr and Falk (2002) and Gächter (2006).
} 
beliefs about others' compliance. Hence, their study highlights the use of belief management as an alternative enforcement strategy. Clearly, further research is needed to study scope and limits of belief management.

\section{Appendix}

\section{A1. Appendix to Section 3 - Threshold Level $\tilde{\theta}$}

From (16) we can easily derive

$$
\tilde{\theta}(n)=\frac{-\tau^{2}}{c(n)}\left\{p s u^{\prime \prime}\left(x_{i}^{a}\right)\left(y+s e_{i}^{*}\right)-(1-p) u^{\prime \prime}\left(x_{i}^{b}\right)\left(y-e_{i}^{*}\right)\right\}
$$

Using $\rho(x)$, the Arrow-Pratt measure of absolute risk aversion, rearranging and substituting for (6), we get

$$
\tilde{\theta}(n)=\frac{(1-p) \tau^{2} u^{\prime}\left(x_{i}^{b}\right)\left\{\rho\left(x_{i}^{a}\right)\left(y+s e_{i}^{*}\right)-\rho\left(x_{i}^{b}\right)\left(y-e_{i}^{*}\right)\right\}}{c(n)\left(1+\tau \rho\left(x_{i}^{a}\right)\left(y+s e_{i}^{*}\right)\right)}>0 .
$$

Non-increasing absolute risk aversion is sufficient for $\tilde{\theta}(n)>0$ to hold, since from $\rho^{\prime}(x) \leq 0$ follows $\rho\left(x_{i}^{a}\right) \geq \rho\left(x_{i}^{b}\right)$. Note further that $c^{\prime}(n) \leq 0$ implies $\partial \tilde{\theta}(n) / n \geq 0$.

\section{A2. Appendix to Section 4}

Applying the implicit function theorem on (17) yields

$$
\frac{d n^{*}}{d p}=\frac{-(1+s) \tau u^{\prime}((1-\tau) y) \frac{1}{c(n)}}{\frac{\partial F^{-1}}{\partial n}-\frac{\partial \hat{\theta}(n)}{\partial n}}<0 .
$$

where we used (7) to derive $\partial z / \partial p$. As we know from (18), the denominator must be positive in a stable equilibrium. This determines the sign of (A.3).

Following the same steps as before, we get

$$
\begin{aligned}
\frac{d n^{*}}{d s} & =\frac{-p \tau u^{\prime}((1-\tau) y) \frac{1}{c(n)}}{\frac{\partial F^{-1}}{\partial n}-\frac{\partial \hat{\theta}(n)}{\partial n}}<0, \\
\frac{d n^{*}}{d \tau} & =\frac{\frac{\partial z}{\partial \tau} \frac{1}{c(n)}}{\frac{\partial F^{-1}}{\partial n}-\frac{\partial \hat{\theta}(n)}{\partial n}}>0
\end{aligned}
$$

with

$$
\frac{\partial z}{\partial \tau}=(1-p(1+s))\left[u^{\prime}((1-\tau) y)-\tau y u^{\prime \prime}((1-\tau) y)\right]>0
$$


Equilibrium Threshold $\tilde{\theta}^{*}\left(n^{*}\right) \quad$ Substituting for (13) we can express (20) as

$$
\frac{d e_{i}^{*}}{d \tau}=\frac{1}{-E[u]^{\prime \prime}}\left\{\frac{\theta_{i} c\left(n^{*}\right)}{\tau}+p s \tau u^{\prime \prime}\left(x_{i}^{a}\right)\left(y+s e_{i}^{*}\right)-(1-p) \tau u^{\prime \prime}\left(x_{i}^{b}\right)\left(y-e_{i}^{*}\right)-\theta_{i} c^{\prime}\left(n^{*}\right) \frac{d n^{*}}{d \tau}\right\} .
$$

The sign of the expression is determined by the term in the curly brackets. Using $\rho(x)$ and (6), we get the threshold

$$
\tilde{\theta}^{*}\left(n^{*}\right)=\frac{(1-p) \tau^{2} u^{\prime}\left(x_{i}^{b}\right)\left\{\rho\left(x_{i}^{a}\right)\left(y+s e_{i}^{*}\right)-\rho\left(x_{i}^{b}\right)\left(y-e_{i}^{*}\right)\right\}}{c\left(n^{*}\right)\left(1+\tau \rho\left(x_{i}^{a}\right)\left(y+s e_{i}^{*}\right)-\tau \frac{c^{\prime}\left(n^{*}\right)}{c\left(n^{*}\right)} \frac{d n^{*}}{d \tau}\right)} .
$$

For $\theta_{i}>\tilde{\theta}^{*}\left(n^{*}\right)$ the term in the curly brackets is positive and hence $d e_{i}^{*} / d \tau>0$. Finally, we compare this threshold with the partial equilibrium threshold, $\tilde{\theta}\left(n^{*}\right)$ from (A.2). As the numerator of (A.2) and (A.8) are the same, but the denominator of (A.8) is bigger, it immediately follows that $\tilde{\theta}>\tilde{\theta}^{*}$ for any $n^{*}$. Moreover, from (A.5) also follows that the denominator of (A.8) is strictly positive. Therefore $\tilde{\theta}^{*}\left(n^{*}\right)>0$.

\section{A3. Appendix to Section 5}

From (28) and (29) we can derive

$$
\frac{d n_{j}^{*}}{d \tau_{j}}=\frac{\frac{\partial z_{j}}{\partial \tau_{j}}}{\left(\sum_{k} \alpha_{j k} c\left(n_{k}^{*}\right)\right)^{2}\left(F_{j}^{\prime}\left(\hat{\theta}_{j}\right)\right)^{-1}+z_{j} \alpha_{j j} c^{\prime}\left(n_{j}^{*}\right)}>0 .
$$

From (30) we know that in any stable equilibrium the denominator must be positive. As $\partial z_{j} / \partial \tau_{j}>0$, we get $d n_{j}^{*} / d \tau_{j}>0$.

Implicitly differentiating (29) further yields

$$
\frac{d n_{j}^{*}}{d n_{k}^{*}}=\frac{-z_{j} \alpha_{j k} c^{\prime}\left(n_{k}^{*}\right)}{\left(\sum_{k} \alpha_{j k} c\left(n_{k}^{*}\right)\right)^{2}\left(F_{j}^{\prime}\left(\hat{\theta}_{j}\right)\right)^{-1}+z_{j} \alpha_{j j} c^{\prime}\left(n_{j}^{*}\right)}>0
$$

as the denominator must be positive in any stable equilibrium. Given that $c^{\prime}\left(n_{k}^{*}\right)<0, d n_{j}^{*} / d n_{k}^{*}$ is strictly positive as long as $\alpha_{j k}>0$. Since we assume $\alpha_{j j}<1$, this always holds in the case of two groups due to (26).

From the first order condition (27) we obtain

$$
\frac{\partial e_{i j}^{*}}{\partial n_{k}}=\frac{\theta_{i j} \alpha_{j k} c^{\prime}\left(n_{k}\right)}{E\left[u_{j}\right]^{\prime \prime}} \geq 0 .
$$




\section{References}

Akerlof, George A. (1980), 'A Theory of Social Custom, of Which Unemployment May be One Consequence', The Quarterly Journal of Economics 94(4), 749-775.

Aitken, Sherie S. and Laura Bonneville (1980), A General Taxpayer Opinion Survey, Internal Revenue Service: Washington DC.

Allingham, Michael and Agnar Sandmo (1972), 'Income Tax Evasion: A Theoretical Analysis', Journal of Public Economics 1, 323-338.

Alm, James, Gary H. McClelland and William D. Schulze (1992), 'Why do people pay taxes?', Journal of Public Economics 48, 21-38.

Alm, James and Benno Torgler (2006), 'Culture differences and tax morale in the United States and in Europe', Journal of Economic Psychology 27(2), 224-246.

Andreoni, James, Brian Erard and Jonathan Feinstein (1998), 'Tax Compliance', Journal of Economic Literature 36, 818-860.

Arbak, Emrah and Marie-Claire Villeval (2006), 'Endogenous Leadership: Selection and Influence', Mimeo, CNRS/GATE.

Baldry, J.C. (1986), 'Tax Evasion is not a Gamble', Economics Letters 22, 333-335.

Bernasconi, Michele (1998), 'Tax evasion and orders of risk aversion', Journal of Public Economics 67(1), 123-134.

Bordignon, Massimo (1993), 'A fairness approach to income tax evasion', Journal of Public Economics 52(3), 345-362.

Bosman, Ronald and Frans van Winden (2002), 'Emotional Hazard in a Power-to-Take Experiment', Economic Journal 112, 147-69

Clotfelter, Charles T. (1983), 'Tax Evasion and Tax Rates: An Analysis of Individual Returns', The Review of Economics and Statistics 65(3), 363-373.

Cowell, Frank A. (1990), Cheating the Government, MIT Press: Cambridge, Mass.

Cullis, John G. and Alan Lewis (1997), Why people pay taxes: From a conventional economic model to a model of social convention, Journal of Economic Psychology 18(2-3), 305-321.

Erard, B. and Feinstein, J. S. (1994), 'The role of moral sentiments and audit perceptions in tax compliance', Public Finance/Finance Publiques 49 (Supplement), 70-89.

Falkinger, Josef (1995), 'Tax evasion, consumption of public goods and fairness', Journal of Economic Psychology 16(1), 63-72.

Fehr, Ernst and Armin Falk (2002), 'Psychological foundations of incentives', European Economic Review 46(4-5), 687-724.

Fellner, Gerlinde, Rupert Sausgruber and Christian Traxler (2006), 'We will make you pay! A Large-Scale Natural Field Experiment on the Collection of Public Broadcasting Fees', in preparation.

Frey, Bruno S. and Benno Torgler (2006), 'Tax Morale and Conditional Cooperation', IEW - Working Papers 286, Institute for Empirical Research in Economics, University of Zurich.

Gächter, Simon (2006), 'Conditional cooperation: Behavioral regularities from the lab and the field and their policy implications', Discussion Papers 2006-03, CeDEx, University of Nottingham.

Gächter, Simon and Elke Renner (2006), 'Leading by Example in the Presence of Free-Rider Incentives', Mimeo, CeDEx, University of Nottingham. 
Gërxhani, Klarita and Arthur Schram (2006), 'Tax evasion and income source: A comparative experimental study', Journal of Economic Psychology 27(3), 402-422.

Gordon, J. P. F. (1989), 'Individual Morality and Reputation Costs as Deterrents to Tax Evasion', European Economic Review 33, 797-805.

Güth, Werner, M.V. Levati and Rupert Sausgruber (2005), 'Tax Morale and (De-)Centralization: An Experimental Study', Public Choice 125(1), 171-188.

Hammar, Henrik, Sverker Jagers and Katarina Nordblom (2005), 'Tax Evasion and the Importance of Trust', Working Papers in Economics No. 179, Göteborg University, Department of Economics.

Hopfensitz, Astrid and Frans van Winden (2005), 'On the interaction of investment and emotions: an experimental study', Mimeo, CREED, Universtiy of Amsterdam.

Kirchler, Erich, Boris Maciejovsky and Friedrich Schneider (2003), 'Everyday representations of tax avoidance, tax evasion, and tax flight: Do legal differences matter?', Journal of Economic Psychology 24(4), 535-553.

Lewis, Alan (1982), The Psychology of Taxation, Martin Roberson: Oxford.

Lewis, Alan (1986), Fiscal Policy: The Importance of Perceptions and Attitudes. In: B. Gilad and S. Kaish (Eds.), The Handbook of Behavioural Economics, JAI Press: New York.

Myerson, Roger B., Gregory B. Pollock and Jeroen Swinkels (1991), 'Viscous Population Equilibria', Games and Economic Behaviour 3(1), 101-109.

Myles, Gareth D., and Robin A. Naylor (1996), 'A Model of Tax Evasion with Group Conformity and Social Customs', European Journal of Political Economy 12, 49-66.

Porcano, Thomas M. (1988), 'Correlates of Tax Evasion', Journal of Economic Psychology 9, 47-67.

Rothstein, Bo (2000), 'Trust, Social Dilemmas and Collective Memories', Journal of Theoretical Politics 12(4), 477-501.

Sandmo, Agnar (2005), 'The theory of tax evasion: A retrospective view,' National Tax Journal 58(4), 643-663.

Schelling, Thomas (1960), The Strategy of Conflict, Harvard University Press: Cambridge.

Schnellenbach, Jan (2006), 'Tax Morale and the Taming of Leviathan', Constitutional Political Economy 17, 115-130.

Spicer, Michael W. and Rodney E. Hero (1985), 'Tax Evasion and Heuristics', Journal of Public Economics 26, 263-267.

Torgler, Benno (2006), Tax Compliance and Tax Morale, forthcoming: Edward Elgar.

Torgler, Benno and Friedrich Schneider (2005), 'Attitudes Towards Paying Taxes in Austria: An Empirical Analysis', Empirica 32(2), 231-250.

Yitzhaki, Shlomo (1974), 'A note on: Income tax evasion: A theoretical analysis', Journal of Public Economics 3, 201-202. 